\title{
Functionalization of graphene nanoplatelets using sugar azide for graphene/epoxy nanocomposites
}

\author{
Saswata Bose $e^{1,2}$ and Lawrence T. Drzal, ${ }^{1, \$}$ \\ ${ }^{1}$ Department of Chemical Engineering and Materials Science, Composite Materials and Structures Center, Michigan State University, \\ MI-48823, USA \\ ${ }^{2}$ Department of Chemical Engineering, Jadavpur University, Kolkata-700032, India
}

\section{Article Info}

Received 31 July 2014

Accepted 9 January 2015

*Corresponding Author

E-mail: Drzal@egr.msu.edu

Tel: (517) 353-7759

\section{Open Access}

DOI: http://dx.doi.org/

10.5714/CL.2015.16.2.101

This is an Open Access article distributed under the terms of the Creative Commons Attribution Non-Commercial License (http://creativecommons.org/licenses/ by-nc/3.0/) which permits unrestricted non-commercial use, distribution, and reproduction in any medium, provided the original work is properly cited.

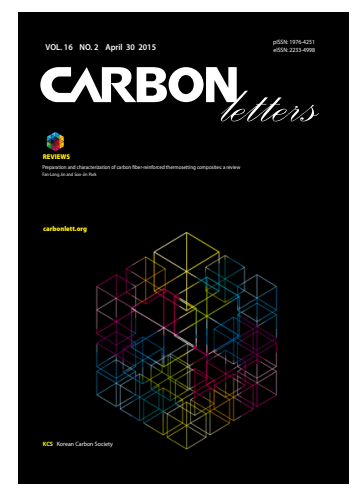

http://carbonlett.org

pISSN: $1976-4251$

elSSN: 2233-4998

Copyright $\odot$ Korean Carbon Society

\begin{abstract}
We report a covalent functionalization of graphene nanoparticles (GnPs) employing $2,3,4$-Tri-O-acetyl- $\beta$-D-xylopyranosyl azide followed by fabrication of an epoxy/functionalized graphene nanocomposite and an evaluation of its thermo-mechanical performance. Successful functionalization of $\mathrm{GnP}$ was confirmed via thermal and spectroscopic study. Raman spectroscopy indicated that the functionalization was on the edge of the graphene sheets; the basal plane was not perturbed as a result of the functionalization. The epoxy/functionalized GnP composite system exhibited an increase in flexural modulus $(\sim 18 \%)$ and glass transition temperature $\left(\sim 10^{\circ} \mathrm{C}\right)$ compared to an un-functionalized $\mathrm{GnP}$ based epoxy composite.
\end{abstract}

Key words: graphene nanoparticles, sugar azide, nanocomposite, spectroscopy, thermomechanical property

\section{Introduction}

Graphene, a one atom thick, 2D lattice of $\mathrm{sp}^{2}$-bonded carbon atoms [1-3], has received significant attention from researchers all over the world owing to its excellent optical, mechanical and electrical properties [4-9]. Graphene sheets are held together by the van der Waals force of attraction. However their inherent tendency towards restacking limits their applications. To achieve stable dispersion of graphene sheets in a polymer, it might be fruitful to incorporate polar groups such as carboxyl, hydroxyl via the covalent/non-covalent functionalization approach. Stable aqueous or organic suspensions of graphene have been achieved via chemical modification and/or oxidation-reduction of graphite oxide [10-12]. However, the functionalization of graphene via chemical oxidation-reduction methods requires the involvement of strong and hazardous acids which in turn destroy the $\mathrm{sp}^{2}$ carbon network and change the $\mathrm{sp}^{2}$ hybridized graphene into an $\mathrm{sp}^{3}$ network with significantly reduced properties.

This report has investigated sugar azide for the edge-functionalization of graphene via covalent bond formation without disrupting the graphene structure. Sugars are very rich in hydroxyl groups and were therefore chosen as a promising material for functionalization. The aim of our study was to create additional $-\mathrm{OH}$ groups on the graphene nanoparticle $(\mathrm{GnP})$ in order to achieve a stable dispersion in a polar organic solvent without disrupting the basal plane of graphene. The additional polar groups are also beneficial as sites for covalent bond formation with an epoxy matrix and thus can contribute to enhancing the themo-mechanical properties of an epoxy/graphene nanocomposite. 


\section{Experimental Details}

\subsection{Materials}

GnP (size: $15 \mu \mathrm{m}$, thickness: 5-7 nm, surface area: $120-150$ $\mathrm{m}^{2} / \mathrm{g}$ ) was supplied by XG Sciences, USA. 2,3,4-Tri-O-acetyl$\beta$-D-xylopyranosyl azide, known as sugar azide was purchased from Sigma Aldrich. Epoxy (Epon 828) was purchased from Miller Stephenson. Ethyl acetate (EtOAc), sodium methoxide (NaOMe) and metaphenylene diamine (MPDA) were purchased from Sigma Aldrich.

\subsection{Functionalization of GnP using Sugar} Azide

A weighed amount of $\mathrm{GnP}$ was mixed with 1,1,2,2-tetrachloroethane (TCE) and the mixture was ultrasonicated for 10 $\mathrm{min}$. The solution was then purged with nitrogen and preheated to $150^{\circ} \mathrm{C}$. Subsequently, sugar azide was dispersed in TCE and the solution was added drop-wise to the reaction mixture over a period of 20-30 $\mathrm{min}$. The temperature was maintained at $150^{\circ} \mathrm{C}$ for $1 \mathrm{~h}$, after which the product was cooled to room temperature under flowing nitrogen. EtOAc was added into the cooled reaction mixture. The crude product will filtered on $0.22 \mu \mathrm{m}$ teflon membrane and washed copiously with EtOAc and methanol $(\mathrm{MeOH})$. The residue left on the filter paper was dried under vacuum at $50^{\circ} \mathrm{C}$ overnight and this product was labelled as azide-functionalized GnP (SAMG-I). SAMG-I was mixed with ethanol (EtOH) followed by the addition of $\mathrm{NaOMe}(30 \%)$ in $\mathrm{MeOH}$. The reaction mixture was stirred under nitrogen for $24 \mathrm{~h}$ at room temperature and then was slowly transferred into distilled water drop by drop. The basic mixture was then neutralized with a few drops of $\mathrm{HCl}$ $(37 \%)$. The deacylated product was then filtered on $0.22 \mu \mathrm{m}$ teflon membrane and repeatedly washed with distilled water and EtOAc. Finally, the (SAMG) was dried at $50^{\circ} \mathrm{C}$ under vacuum overnight.

\subsection{Fabrication of epoxy/GnP composite}

Epoxy was mixed with SAMG using a Flack-tek speed mixer for $2 \mathrm{~min}$ at $2500 \mathrm{rpm}$ followed by ultrasonication for $30 \mathrm{~min}$ at 60 watts. The solution was degassed in vacuum for $5 \mathrm{~min}$. MPDA was added to the mixture and again mixed using a Flacktek speed mixer for $2 \mathrm{~min}$ at $2000 \mathrm{rpm}$. The entire mixture was degassed for $5 \mathrm{~min}$ at $70^{\circ} \mathrm{C}$. The solution was poured into a silicone mold to make coupons. The mixture was cured at $75^{\circ} \mathrm{C}$ for $2 \mathrm{~h}$ and at $125^{\circ} \mathrm{C}$ for another $2 \mathrm{~h}$. The coupons were polished prior to testing.

\section{Measurements}

Raman spectra were recorded in the range of 500 to 3500 $\mathrm{cm}^{-1}$ in a LabRAM ARAMIS confocal Raman microscope using a He-Cd laser beam with a wavelength of $532 \mathrm{~nm}$. X-ray photo electron spectroscopy (XPS) was performed with a Perkin Elmer Phi 5600 ESCA (Kratos Analytical Ltd., UK), using

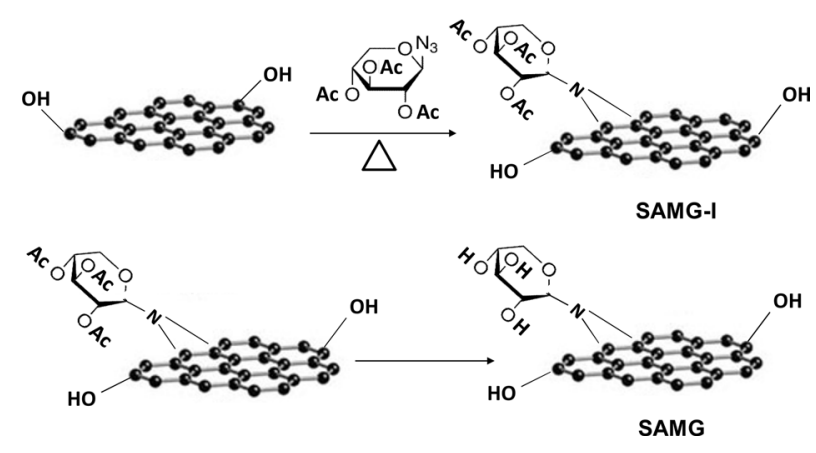

Scheme 1. Pathway of SAMG formation.

an unmonochromatized $\mathrm{Mg}-\mathrm{K} \alpha$ Xray source at a take-off angle of $45^{\circ}$. Dynamic mechanical analyses (DMA 800, TA instruments) of the samples was conducted from room temperature to $200^{\circ} \mathrm{C}$ in the single cantilever mode at a heating rate and frequency of $3^{\circ} \mathrm{C} / \mathrm{min}$ and $1 \mathrm{~Hz}$, respectively. Thermogravimetric analysis (TGA) of the neat cured epoxy and its composites with GnP was carried out using TGA 500 (TA instruments, USA) with a heating rate of $10^{\circ} \mathrm{C} / \mathrm{min}$ from room temperature to $700^{\circ} \mathrm{C}$ in air. Flexural properties of the samples were tested using a United Testing System (UTS, SFM-20 load frame) with a 100 pound load cell according to ASTM D790. The morphology of the fracture surface was observed by Scanning electron microscopy (SEM; Carl Zeiss Varible Pressure SEM EVO LS25). Samples were sputter-coated with tungsten prior to their SEM observation.

\section{Proposed Mechanism}

Sugar azide, a highly reactive substance, forms nitrenes by thermal or photocatalytic decomposition. The in-situ formed nitrenes react with the double bonds at the edges of $\mathrm{GnP}$ to form the azide adduct. Finally, the -OAc groups were hydrolyzed to form hydroxyl terminated azide modified GnP (SAMG). The pathway of SAMG formation is shown in Scheme 1.

\section{Results and Discussion}

\subsection{Characterization of functionalized graphene (SAMG)}

4.1.1. X-ray photo electron spectroscopy

Fig. 1a and $b$ show the C-1s XPS patterns of $\mathrm{GnP}$ and SAMG, respectively. The spectrum of GnP can be deconvoluted into two different peaks. The peaks at 284.8 and 289.3 $\mathrm{eV}$ have been assigned to the $\mathrm{C}-\mathrm{C} / \mathrm{C}=\mathrm{C}$ in the aromatic rings, and $\mathrm{O}-\mathrm{C}=\mathrm{O}$ groups, respectively [13-15]. However, the $\mathrm{C}-1 \mathrm{~s}$ XPS patterns of SAMG have been deconvoluted into four different peaks. Two new peaks at 285.6 and $286.5 \mathrm{eV}$ have been assigned to $\mathrm{C}-\mathrm{N}$ and $\mathrm{C}-\mathrm{OH}$ groups, respectively. The $\mathrm{N}-1 \mathrm{~s}$ spectrum of SAMG is shown in the inset of Fig. 1b. The welldefined peaks at 398.9 and $401.7 \mathrm{eV}$ clearly suggest the existence of bonded nitrogen in SAMG. 

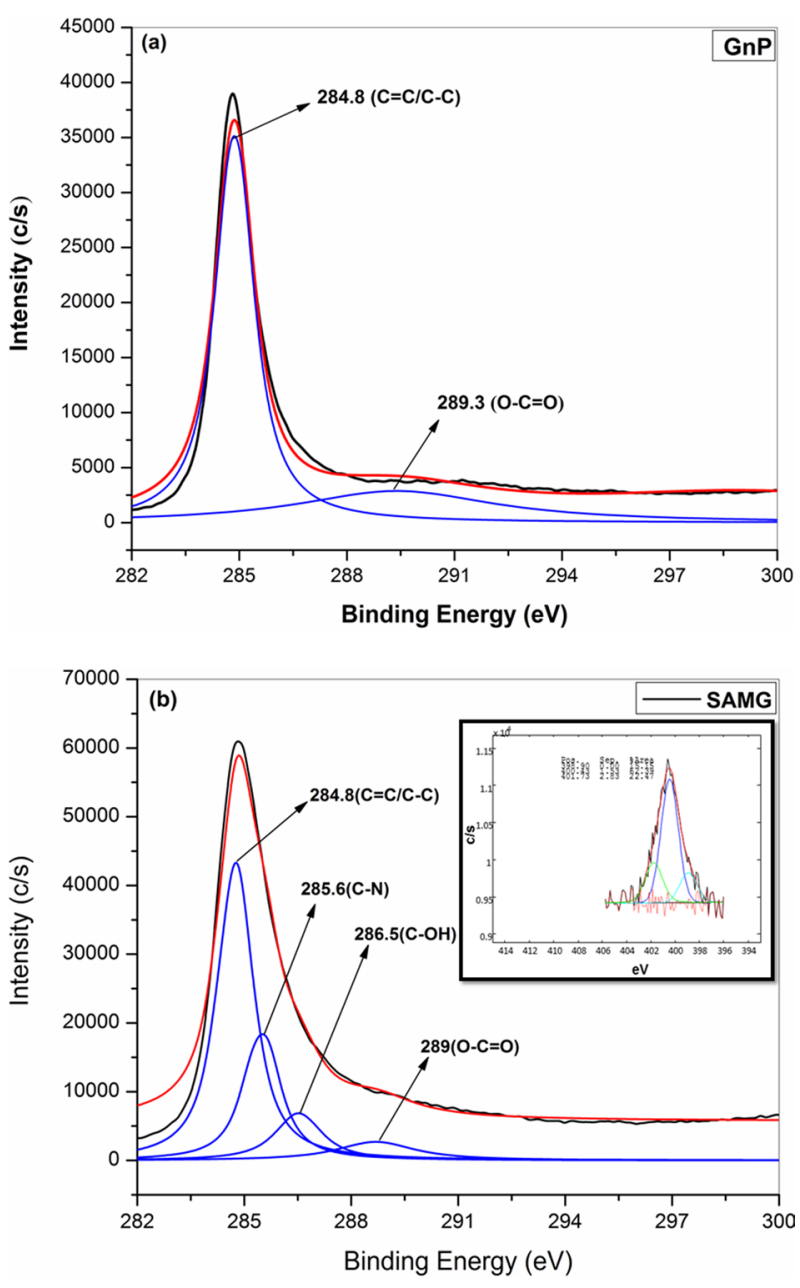

Fig. 1. X-ray photo electron spectroscopy of (a) neat graphene nanoparticle (GnP) and (b) SAMG.

\subsubsection{Atomic force microscopy}

Atomic force microscopy (AFM) characterization allows the number of graphene layers to be identified. The AFM image of SAMG is shown in Fig. 2. The thickness of SAMG, measured from the height profile of the AFM image, is about $1.45 \mathrm{~nm}$. The thickness of the SAMG sheets is drastically reduced compared to neat $\mathrm{GnP}(5-7 \mathrm{~nm})$ indicating the successful exfoliation of graphene layers upon functionalization. However, the difference in height value of the SAMG compared to the theoretical value of a monolayer of graphene is due to 1) the presence of the oxygenated moiety as a result of functionalization and 2) the resulting few layers (4-5) of graphene.

\subsubsection{Thermogravimetric analysis}

TGA thermograms of GnP and SAMG are shown in Fig. 3 and the derivative plot (DTG) is shown in the inset of Fig. 3. Neat GnP is quite stable up to $450^{\circ} \mathrm{C}$. The weight loss after $450^{\circ} \mathrm{C}$ is due to degradation of the carbon skeleton of GnP. On the other hand, SAMG exhibited almost $5 \%$ weight loss at $400^{\circ} \mathrm{C}$. The DTG curve showed that the thermal history of SAMG involves a twostep degradation process. The initial weight loss in the temperature range of $150^{\circ} \mathrm{C}-210^{\circ} \mathrm{C}$ corresponds to a combined weight loss due

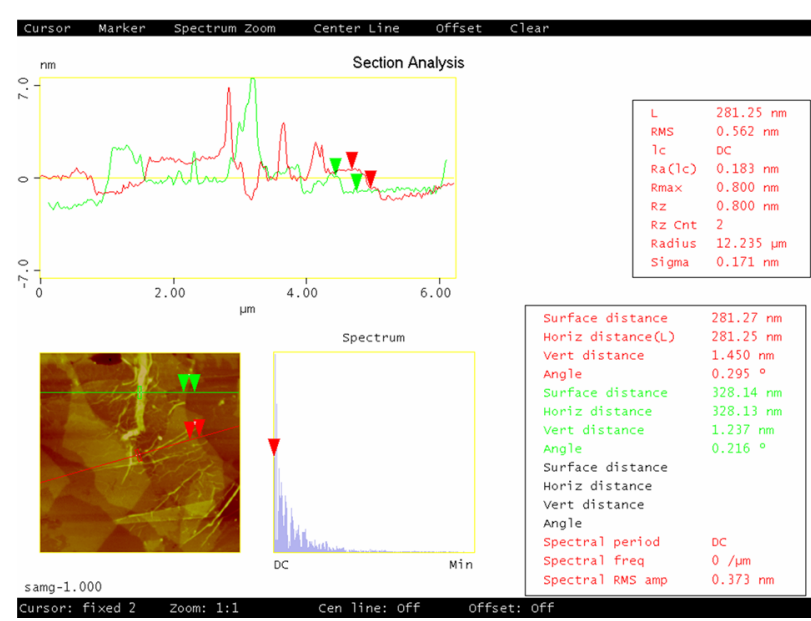

Fig. 2. Non-contact mode atomic force microscopy image of SAMG on mica substrate.

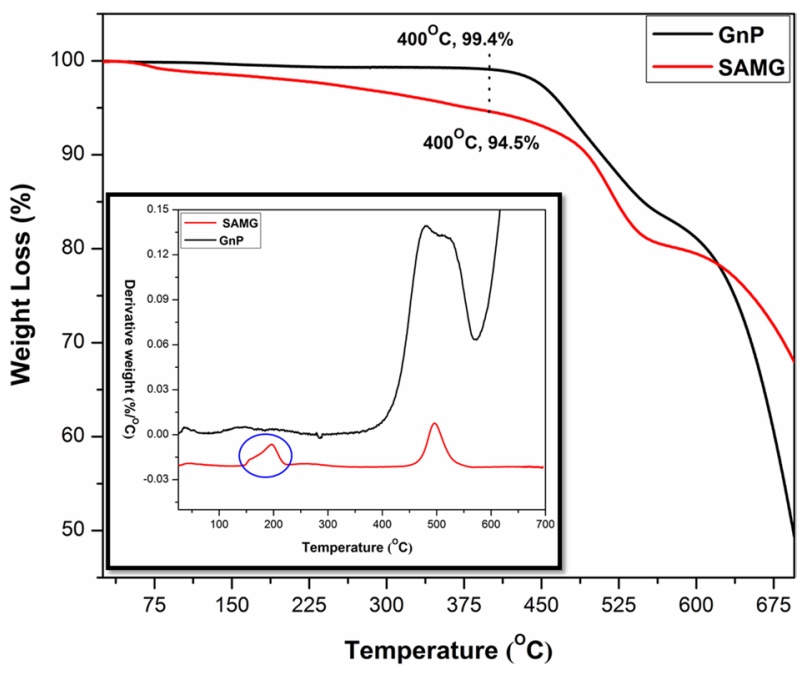

Fig. 3. Thermogravimetric analysis thermograms of graphene nanoparticle $(G n P)$ and SAMG. The derivative curve is shown in the inset.

to degradation of the azide and oxygenated groups, which were formed upon functionalization. The final weight loss at around $500^{\circ} \mathrm{C}$ is due to cleavage of the carbon skeleton of GnP.

\subsubsection{Raman spectroscopy}

Raman spectroscopic analysis is an important tool for defining the quality of graphene. Fig. $4 \mathrm{a}$ and $\mathrm{b}$ show the Raman spectra of the GnP and SAMG, respectively. The Raman spectrum of the $\mathrm{GnP}$ has a characteristic D band at $1352 \mathrm{~cm}^{-1}$ (the breathing mode of $\mathrm{C}-\mathrm{sp}^{2}$ atoms in the rings, which is related to disorder within the structure) and a $\mathrm{G}$ band at $1572 \mathrm{~cm}^{-1}$ (the in-plane bond stretching motion of C-sp ${ }^{2}$ atoms) [16-19]. However, the Raman spectrum of the SAMG (Fig. 4b) showed an increment in the $\mathrm{I}_{\mathrm{D}}: \mathrm{I}_{\mathrm{G}}$ ratio, from 0.54 to 0.77 , which can be attributed to an enhancement in defect concentration due to functionalization, i.e., the conversion of $\pi$-bonded $\mathrm{C}$-sp ${ }^{2}$ carbons to $\mathrm{C}$-sp ${ }^{3}$ ones. Moreover, the higher $\mathrm{I}_{\mathrm{D}} / \mathrm{I}_{\mathrm{G}}$ ratio signifies a higher degree of covalent functionalization [20]. However, the shape of the ' $G$ ' 

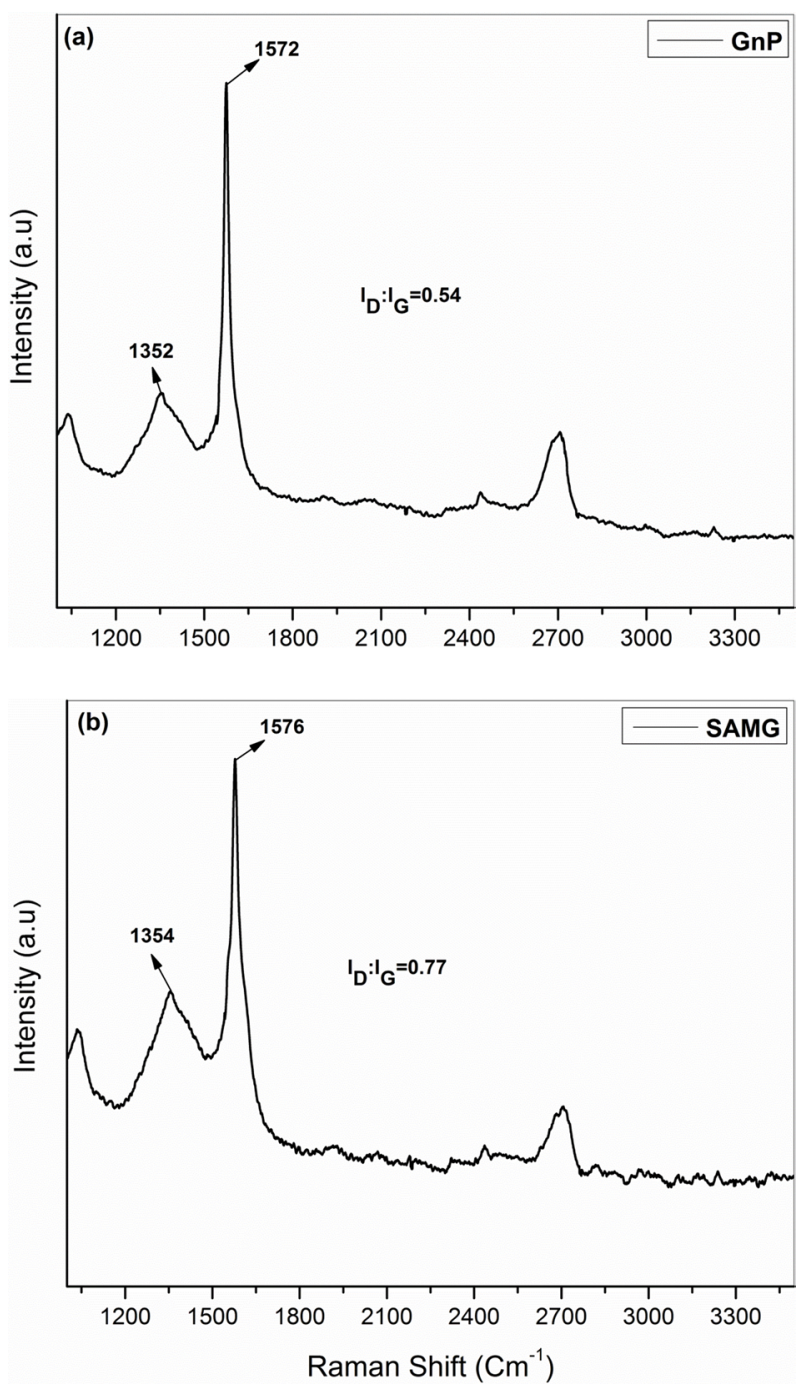

Fig. 4. Raman spectroscopy of (a) neat graphene nanoparticle (GnP) and (b) SAMG.

band at $1579 \mathrm{~cm}^{-1}$ was observed to be sharp, suggesting that the functionalization occurred at the edges without disrupting the basal plane of the GnP.

\subsubsection{Scanning electron microscopy}

SEM micrographs of neat GnP and SAMG are shown in Fig. $5 \mathrm{a}$ and $\mathrm{b}$. The surface of the GnP was smooth and clean (Fig. 5a). However, while extensive functionalization did not affect the basal plane or the flaky structure of GnP, the surface of the SAMG became rough and wavy after functionalization (Fig. $5 \mathrm{~b}$ ).

\subsection{Thermo-mechanical performance of ep- oxy/SAMG composite}

4.2.1. Thermogravimetric analysis

The thermal stability of neat epoxy and its nanocomposites is shown in Fig. 6. The onset degradation temperature of neat epoxy appears at $355^{\circ} \mathrm{C}$. However, the onset degradation temperature was reduced to $339^{\circ} \mathrm{C}$ for the epoxy $/ \mathrm{GnP}(2 \mathrm{wt} \%)$ nanocomposite.

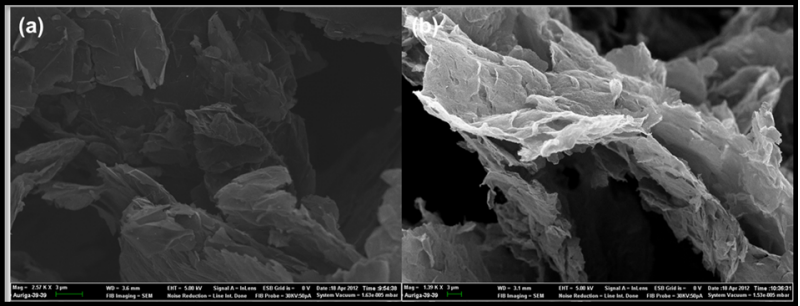

Fig. 5. High magnification scanning electron microscopy image of (a) neat graphene nanoparticle and (b) SAMG.

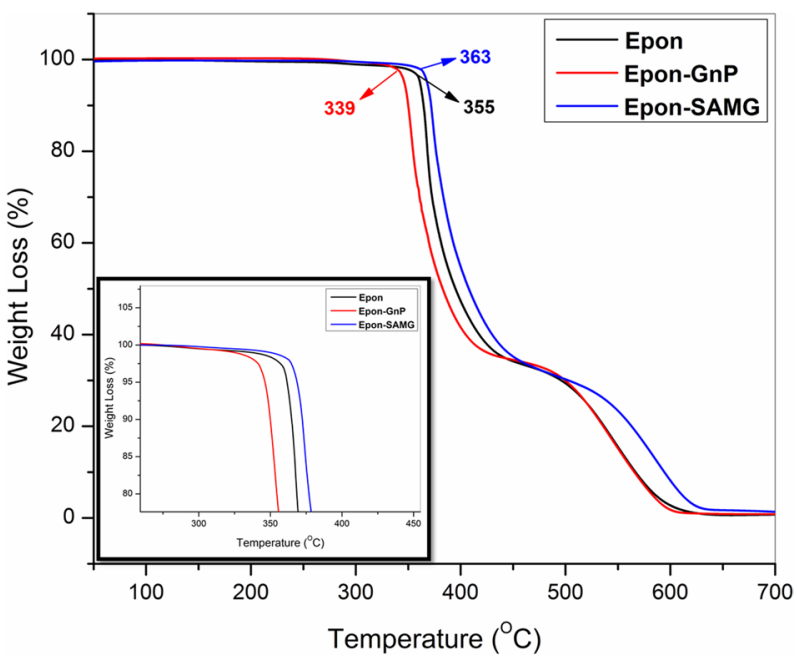

Fig. 6. Thermogravimetric analysis thermograms of neat epoxy and epoxy/graphene nanoparticle (GnP) nanocomposites. A magnified image of onset degradation is shown in the inset.

At $50 \%$ weight loss, the degradation temperatures of neat epoxy, epoxy/GnP (2 wt $\%)$, and epoxy/SAMG (2 wt $\%)$ nanocomposites were observed to be $394^{\circ} \mathrm{C}, 382^{\circ} \mathrm{C}$, and $408^{\circ} \mathrm{C}$, respectively. The decrease in the thermal stability of the epoxy/GnP (2 wt $\%)$ nanocomposite was probably due to poor interfacial adhesion between filler and matrix resulting from the inhomogeneous distribution of GnP particles throughout the matrix. On the other hand, functionalization resulted in the creation of polar groups which in turn facilitated the homogeneous distribution of SAMGs throughout the matrix. Homogeneously distributed functionalized graphene layers could reduce the emission of small gaseous molecules resulting in delayed thermal degradation of the nanocomposites compared to neat epoxy and the epoxy/GnP composite.

\subsubsection{Dynamic mechanical analyses}

The variation of loss tangent (Tan $\delta$ ) as a function of temperature is shown in Fig. 7. Tan $\delta$ is the ratio of the loss modulus to the storage modulus and is very sensitive to structural transformations. Tan $\delta$ for neat epoxy appears at $153.7^{\circ} \mathrm{C}$, which is assumed to be the glass transition temperature $(\mathrm{Tg})$ of the neat epoxy. However, in the presence of $\mathrm{GnP}$, the $\mathrm{Tg}$ has shifted to a lower temperature region $\left(144.8^{\circ} \mathrm{C}\right)$ suggesting partial immiscibility between the matrix and filler, leading to the poor interfacial adhesion. However, functionalization resulted in a substantial increment in $\mathrm{Tg}$, suggesting the formation of better 


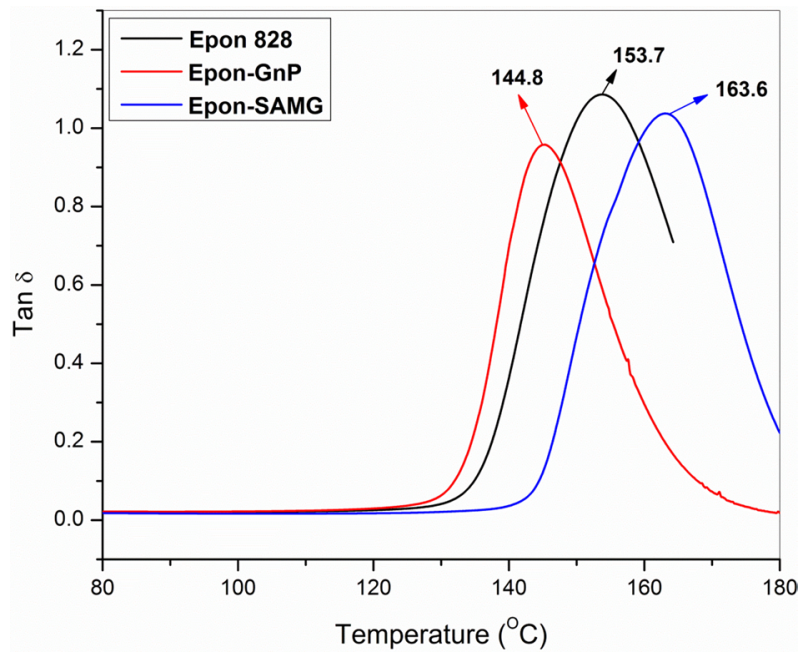

Fig. 7. Variation of glass transition temperature as a function of temperature of neat epoxy and epoxy/graphene nanoparticle (GnP) nanocomposites.

Table 1. Thermal stability and dynamic mechanical properties of neat epoxy and its nanocomposites with $\mathrm{GnP}$

\begin{tabular}{ccccc} 
Sample & $\begin{array}{c}\text { Onset } \\
\text { degradation } \\
\text { temperature } \\
\left({ }^{\circ} \mathrm{C}\right)\end{array}$ & $\begin{array}{c}\text { Degradation } \\
\text { temperature at } \\
50 \% \text { weight } \\
\text { loss }\left({ }^{\circ} \mathrm{C}\right)\end{array}$ & $\begin{array}{c}\text { Glass } \\
\text { transition } \\
\text { temperature } \\
\left({ }^{\circ} \mathrm{C}\right)\end{array}$ & ${\text { Tan } \delta_{\max }}$ \\
\hline Neat Epon & 355 & 394 & 153.7 & 1.09 \\
$\begin{array}{c}\text { Epon/GnP } \\
(2 \%)\end{array}$ & 339 & 384 & 144.8 & 0.95 \\
$\begin{array}{c}\text { Epon/SAMG } \\
(2 \%)\end{array}$ & 363 & 408 & 163.6 & 1.03 \\
\hline
\end{tabular}

GnP: graphene nanoparticle.

adhesion and a strong interface between SAMG and epoxy. Superior adhesion allows better stress transfer from filler to matrix. The details of the thermal stability and Tg's of neat epoxy and nanocomposites have been summarized in Table 1.

\subsubsection{Scanning electron microscopy}

Fractured surfaces (from flexural tests) of neat epoxy and epoxy nanocomposites were investigated by SEM and the micrographs are presented in Fig. 8a-d. The fracture surfaces of neat epoxy were smooth and clean (Fig. 8a). The epoxy/GnP (2 wt\%) nanocomposite displayed the clear formation of $\mathrm{GnP}$ aggregates. The aggregates were very poorly distributed in the matrix, and this was responsible for its poor thermal and mechanical properties (Fig. 8b). On the other hand, functionalization caused a more homogeneous distribution of SAMGs throughout the matrix (Fig. 8c). The high magnification SEM image of epoxy/ SAMG (2 wt $\%$ ) nanocomposite (Fig. 8d) further shows that the wavy SAMG particles were embedded into the matrix, suggesting better wetting and stronger bonding between epoxy and SAMG, which in turn caused an improvement in thermal and mechanical properties to a reasonable extent.

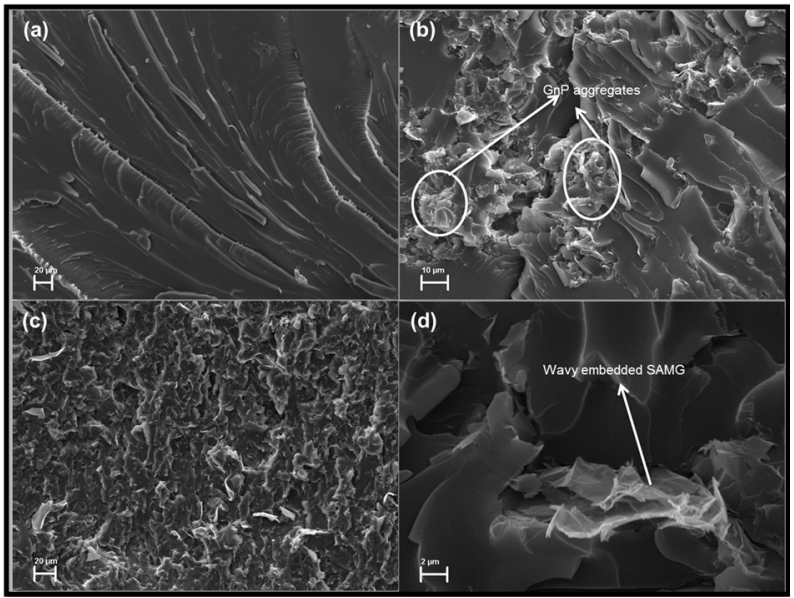

Fig. 8. Sanning electron microscopy image (flexural fractured) of (a) neat graphene nanoparticle (GnP); (b) epoxy/GnP nanocomposite; epoxy/ SAMG nanocomposite at (c) lower and (d) higher magnification.

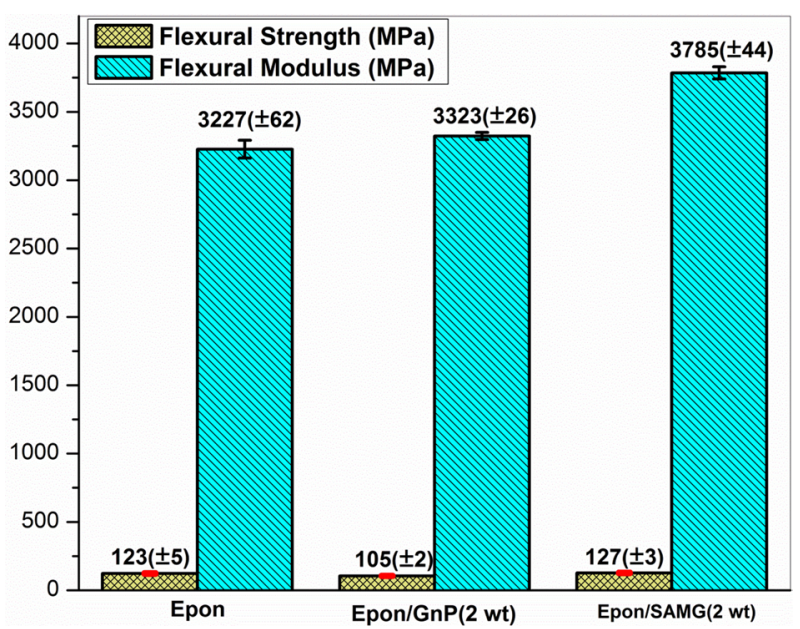

Fig. 9. Flexural properties of neat epoxy and epoxy/graphene nanoparticle $(\mathrm{GnP})$ nanocomposites.

\subsubsection{Flexural properties}

Fig. 9 represents the effect of functionalization on the flexural modulus and strength of GnP/epoxy nanocomposites. Functionalization resulted in an $18 \%$ improvement in flexural modulus as compared to neat epoxy. Functionalization of $\mathrm{GnP}$ results in: 1) creation of groups which can react with the epoxy matrix and 2) prevention of restacking of $\mathrm{GnP}$ nanoparticles, which helps produce a more homogeneous distribution. The flexural strength of the epoxy/SAMG (2 wt $\%$ ) nanocomposite system showed a negligible increment.

\section{Conclusions}

Nitrogen-linked graphene was synthesized using sugar azide via the formation of nitrene as an intermediate. Polar groups created via functionalization facilitated hybrid nanocomposite formation with improved thermo-mechanical properties. Func- 
tionalization of graphene was verified with spectroscopic studies and thermal analysis. The SAMG nanocomposite showed a reasonable increase in glass transition temperature as compared to neat matrix and the epoxy/GnP composite, suggesting strong interfacial adhesion between the functionalized graphene and the epoxy. Morphological observation revealed that the functionalized GnPs were rough, wavy and were embedded into the matrix, confirming the strong adhesion between filler and matrix. The flexural modulus was $18 \%$ higher compared to neat epoxy.

\section{Acknowledgements}

This material is based upon work supported by the United States Army under Contract No. W56HZV-13-C-0401. The authors are thankful to XG Sciences, Inc. for supplying the graphene nanoplatelets.

\section{References}

[1] Fan X, Peng W, Li Y, Li X, Wang S, Zhang G, Zhang F. Deoxygenation of exfoliated graphite oxide under alkaline conditions: a green route to graphene preparation. Adv Mater, 20, 4490 (2008). http://dx.doi.org/10.1002/adma.200801306.

[2] Geim AK, Novoselov KS. The rise of graphene. Nat Mater, 6, 183 (2007). http://dx.doi.org/10.1038/nmat1849.

[3] Wang G, Yang J, Park J, Gou X, Wang B, Liu H, Yao J. Facile synthesis and characterization of graphene nanosheets. J Phys Chem C, 112, 8192 (2008). http://dx.doi.org/10.1021/jp710931h.

[4] Lee C, Wei X, Kysar JW, Hone J. Measurement of the elastic properties and intrinsic strength of monolayer graphene. Science, 321 385 (2008). http://dx.doi.org/10.1126/science.1157996.

[5] Chen H, Müller MB, Gilmore KJ, Wallace GG, Li D. Mechanically strong, electrically conductive, and biocompatible graphene paper. Adv Mater, 20, 3557 (2008). http://dx.doi.org/10.1002/ adma.200800757.

[6] Stankovich S, Dikin DA, Dommett GHB, Kohlhaas KM, Zimney EJ, Stach EA, Piner RD, Nguyen ST, Ruoff RS. Graphenebased composite materials. Nature, 442, 282 (2006). http://dx.doi. org/10.1038/nature04969.

[7] Balandin AA, Ghosh S, Bao W, Calizo I, Teweldebrhan D, Miao F, Lau CN. Superior thermal conductivity of single-layer graphene. Nano Lett, 8, 902 (2008). http://dx.doi.org/10.1021/n10731872.

[8] Gómez-Navarro C, Weitz RT, Bittner AM, Scolari M, Mews A,
Burghard M, Kern K. Electronic transport properties of individual chemically reduced graphene oxide sheets. Nano Lett, 7, 3499 (2007). http://dx.doi.org/10.1021/n1072090c.

[9] Zhang Y, Tang TT, Girit C, Hao Z, Martin MC, Zettl A, Crommie MF, Shen YR, Wang F. Direct observation of a widely tunable bandgap in bilayer graphene. Nature, 459, 820 (2009). http:// dx.doi.org/10.1038/nature08105.

[10] Li D, Müller MB, Gilje S, Kaner RB, Wallace CG. Processable aqueous dispersions of graphene nanosheets. Nat Nanotechnol, 3, 101 (2008). http://dx.doi.org/10.1038/nnano.2007.451.

[11] Si Y, Samulski ET. Synthesis of water soluble graphene. Nano Lett, 8, 1679 (2008). http://dx.doi.org/10.1021/n1080604h.

[12] Bai H, Xu Y, Zhao L, Li C, Shi G. Non-covalent functionalization of graphene sheets by sulfonated polyaniline. Chem Commun, 13, 1667 (2009). http://dx.doi.org/10.1039/B821805F.

[13] Bose S, Kuila T, Mishra AK, Kim NH, Lee JH. Dual role of glycine as a chemical functionalizer and a reducing agent in the preparation of graphene: an environmentally friendly method. J Mater Chem, 22, 9696 (2012). http://dx.doi.org/10.1039/C2JM00011C.

[14] Zhou X, Zhang J, Wu H, Yang H, Zhang J, Guo S. Reducing graphene oxide via hydroxylamine: a simple and efficient route to graphene. J Phys Chem C, 115, 11957 (2011). http://dx.doi. org/10.1021/jp202575j.

[15] Lin Z, Yao Y, Li Z, Liu Y, Li Z, Wong CP. Solvent-assisted thermal reduction of graphite oxide. J Phys Chem C, 114, 14819 (2010). http://dx.doi.org/10.1021/jp1049843.

[16] Kudin KN, Ozbas B, Schniepp HC, Prud'homme RK, Aksay IA, Car R. Raman spectra of graphite oxide and functionalized graphene sheets. Nano Lett, 8, 36 (2008). http://dx.doi.org/10.1021/ n1071822y.

[17] Cançado LG, Pimenta MA, Neves BRA, Dantas MSS, Jorio A. Influence of the atomic structure on the Raman spectra of graphite edges. Phys Rev Lett, 93, 247401 (2004). http://dx.doi org/10.1103/PhysRevLett.93.247401.

[18] Ferrari AC. Raman spectroscopy of graphene and graphite: disorder, electron-phonon coupling, doping and nonadiabatic effects. Solid State Commun, 143, 47 (2007). http://dx.doi. org/10.1016/j.ssc.2007.03.052.

[19] Bose S, Kim NH, Kuila T, Lau KT, Lee JH. Electrochemical performance of a graphene-polypyrrole nanocomposite as a supercapacitor electrode. Nanotechnology, 22, 295202 (2011). http:// dx.doi.org/10.1088/0957-4484/22/29/295202.

[20] Leinonen H, Pettersson M, Lajunen M, Water-soluble carbon nanotubes through sugar azide functionalization. Carbon, 49, 1299 (2011). http://dx.doi.org/10.1016/j.carbon.2010.11.049. 